\title{
Pharmacological Evaluation of Bacopa monnieri Extract against Depressive like Behavior Induced by Ethanol Withdrawal in Rats
}

\author{
Lalit Sharma ${ }^{1}$, Aditi Sharma ${ }^{2}$, Girdhari Lal Gupta ${ }^{3, *}$, Gopal Singh Bisht ${ }^{4, *}$
}

\section{Lalit Sharma', \\ Aditi Sharma², Girdhari Lal Gupta ${ }^{3, *}$, Gopal Singh Bisht $^{4, *}$}

\begin{abstract}
'Department of Pharmacy, Jaypee University of Information Technology, Waknaghat, Solan, Himachal Pradesh, INDIA.

${ }^{2} S$ chool of Pharmaceutical Sciences, Shoolini University, Solan, Himachal Pradesh, INDIA.

${ }^{3}$ Department of Pharmacology, SPPSPTM, SVKM'S NMIMS University, Mumbai, Maharashtra- 400 056, INDIA. ${ }^{4}$ Department of BT and BI, Jaypee University of Information Technology, Waknaghat, Solan, Himachal Pradesh, INDIA.
\end{abstract}

\section{Correspondence}

Dr. Girdhari Lal Gupta

Associate Professor, Department of Pharmacology, SPPSPTM, SVKM'S NMIMS University, Mumbai, Maharashtra, INDIA.

Phone no : +919082689265

E-mail: girdhari_gupta@rediffmail.com

\section{Dr. Gopal Singh Bisht}

Associate Professor, Department of BT and $\mathrm{BI}$, Jaypee University, Waknaghat, Solan, Himachal Pradesh, INDIA.

Phone no: +91-8894135650

Email: bisht.gopal@gmail.com

History

- Submission Date: 30-05-2018;

- Review completed: 11-07-2018;

- Accepted Date: 20-09-2018

DOI : 10.5530/pj.2018.6s.9

Article Available online http://www.phcogi.com/v10/i6s

\section{Copyright}

(C) 2018 Phcog.Net. This is an openaccess article distributed under the terms of the Creative Commons Attribution 4.0 International license.

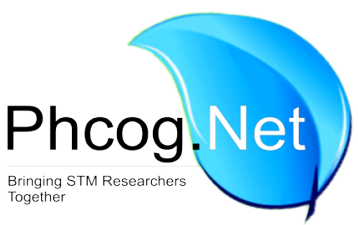

\begin{abstract}
Background: Alcohol withdrawal syndrome lead to relapse to alcohol use and depression is the most common symptom of withdrawal. Bacopa monnieri is a traditional memory enhancer and has reported antidepressant properties as well. Objective: The present study was designed to evaluate the protective effects of Bacopa monnieri extract in alcohol withdrawal depressive-like behavior in alcohol-dependent rats. Methods: Plant drug was extracted with ethanol $(70 \% \mathrm{v} / \mathrm{v})$ using soxhlet extraction. Ethanol $7.2 \%$, v/v was given to the rats in a liquid diet for 21 days and then was withdrawn from the diet and animals were observed at $6^{\text {th }}$ and $24^{\text {th }} \mathrm{h}$ for withdrawal signs like depressive behavior and locomotor hyperactivity. Results: The phytochemical testing of extract revealed the presence of flavonoids, alkaloids, steroids, and tannins. Bacopa monnieri extract $(100,200$ and $300 \mathrm{mg} / \mathrm{kg}$, oral) and fluoxetine $(10 \mathrm{mg} / \mathrm{kg}$ i.p) treatment at the $6^{\text {th }}$ and $24^{\text {th }} \mathrm{h}$ of ethanol withdrawal produced the significant $(p<0.001)$ decrease in the immobility time as compared to the disease control rats when tested on forced swim test and tail suspension test. Bacopa monnieri extract and fluoxetine treatment produced significant $(p<0.001)$ inhibitory effects on locomotor hyperactivity as well. Histopathological examination did not show any remarkable pathological and microscopic changes. Conclusion: Findings from the present study showed that Bacopa monnieri extract treatment has beneficial effects on ethanol withdrawal depressive-like behavior in rats.

Key words: Bacopa monnieri, Ethanol withdrawal syndrome, Depression, Locomotor hyperactivity, Histopathology.
\end{abstract}

\section{INTRODUCTION}

Alcoholism is a chronic, relapsing disorder which is characterized by compulsive alcohol drinking and loss of control over ethanol intake. Alcohol withdrawal syndrome is a life-threatening condition occurring after abrupt cessation of constant heavy alcohol consumption. ${ }^{1}$ Withdrawal symptoms usually appear within 6-24 h of abstinence from alcohol. ${ }^{2}$ Symptoms include rise in blood pressure, anxiety, hyperreflexia, tremors, irritability and depression, which may progress to severe forms such as seizures, delirium tremens (DTs), confusion, excessive hallucinations and severe autonomic instability which may lead to death in some cases. ${ }^{3-4}$ Alcohol withdrawal functions as an unconditioned stressor for stimulating unconditioned withdrawal responses, which leads to the activation of several brain areas, especially the areas that are involved in the modulation and expression of anxiety and depressive-like behaviors such as the amygdala, hypothalamus and hippocampus. ${ }^{5-6}$ Long-term alcohol exposure decreases the number of inhibitory gammaaminobutyric acid (GABA) receptors and in compensation, there is upregulation of excitatory N-methyl$\mathrm{D}$-aspartate glutamate (NMDA) receptors. In alcohol

additive individuals, abstinence of ethanol unmask these neuroadaptations which leads to symptoms of the alcohol withdrawal. ${ }^{7}$ At present treatment choices for alcohol withdrawal syndrome are very few such as Benzodiazepines, Disulfiram, Naltrexone, Acamprosate and among all benzodiazepines are the only drug of choice for treatment of alcohol withdrawal syndrome, but their use is associated with various side effects such as sedation, cognitive impairment and have addictive properties which create a limitation to their use. ${ }^{8-9}$ Therefore, the determination of new potent and therapeutically beneficial drugs for the treatment of alcohol withdrawal symptoms is very important.

Herbal medicines are recognized as the major source of therapeutics and are the first choice in health care treatment nowadays as they are better compatible with the human body and have minimal side effects and desirable outcomes. ${ }^{10-11}$ Bacopa monnieri commonly known as "Brahmi," and also referred to as Bacopa monniera, Herpestis monniera and water hyssop is a perennial creeping plant which belongs to the family Scrophulariaceae and grows throughout

Cite this article: Sharma L, Sharma A, Gupta GL, Bisht GS. Pharmacological Evaluation of Bacopa monnieri Extract against Depressive like Behavior Induced by Ethanol Withdrawal in Rats. Pharmacog J. 2018;10(6)Suppl:s48-s53. 
East Asia and the United States. ${ }^{12}$ The entire plant is used medicinally. In Ayurveda, it is used for the treatment of anxiety and in improving intellect and memory for several centuries. ${ }^{13}$ Bacopa monnieri is also claimed to be useful in the treatment of neuropharmacological disorders like insomnia, depression, psychosis, insanity, stress and epilepsy. ${ }^{14}$ Bacopa monnieri is reported to possess analgesic, anti-inflammatory, sedative, antipyretic, anti-lipid peroxidative and free radical scavenging activities. ${ }^{15-16}$ The plant is anticancerous and also used as a tranquilizer. The presence of steroidal saponins called as Bacosides A and B in Bacopa monnieri mainly attributes to its several pharmacological properties. ${ }^{17}$ Major chemical constituents isolated and characterized from the alcoholic extract of Bacopa monnieri are dammarane type triterpenoid saponins with jujubogenin and pseudojujubogenin as the aglycones, including bacosides A1- A3, bacopasaponins A-G and bacopasides $\mathrm{I}-\mathrm{V} .^{18}$ In animal studies, extracts of Bacopa monnieri have been found to enhance learning ability and various aspects of other mental functions. ${ }^{17,19}$ Bacopa monnieri extract also appears to have significant antioxidant activity in the brain. ${ }^{20}$ Reduction of both anxiety and depression by Bacopa monnieri also demonstrated in animal research. ${ }^{21-22}$ The previous studies reported the antidepressant properties of the Bacopa monnieri in normal rats, while antidepressant properties of Bacopa monnieri using an ethanol withdrawal model have never been studied. Therefore the present investigation was designed to explore the beneficial effects of Bacopa monnieri extract in depressive-like behavior induced by ethanol withdrawal in rats.

\section{MATERIALS AND METHODS}

\section{Chemicals and reagents}

All the chemicals/reagents used in the study were of analytical grade, solvents like petroleum ether, chloroform, ethyl acetate, ethanol, hydrochloric acid were purchased from Merck Mumbai, India and chemicals like Sodium hydroxide, Ferric chloride, Vanillin, were purchased from Himedia, India. The reagents like Wagner's reagent, Dragendorff's reagent, Hagers's reagent, Lieberman Buchard reagent, Millions reagent, Ferric chloride reagent were purchased from Merck Mumbai, India.

\section{Plant Material}

Dried whole plant of Bacopa monnieri (Bath number: ERD-92) has been purchased from Natural Remedies, Bangalore. The whole plant was coarsely powdered with a mechanical grinder and passed through sieve number 60 and stored in an airtight container. The coarsely powdered plant material was subjected to defatting with petroleum ether $\left(30^{\circ}-40^{\circ} \mathrm{C}\right)$. The defatted air-dried plant powder has been extracted by Soxhlet apparatus using $70 \% \mathrm{v} / \mathrm{v}$ of ethanol (hydroalcoholic) at $50^{\circ} \mathrm{C}$ for $48 \mathrm{~h}$. The solvent is recovered by evaporation under reduced pressure using a rotary evaporator (Heidolph, Germany). The semisolid mass has been further lyophilized (New Brunswick) at $-40^{\circ} \mathrm{C}$ for $24 \mathrm{~h}$. The obtained dry powder of the plant is being stored at $-20^{\circ} \mathrm{C}$ till further use.

\section{Phytochemical screening of the plant extract}

The phytochemical investigation of the prepared hydroalcoholic extract was carried out for the presence of flavonoids (Shinoda's test), alkaloids (Wagner's test), tannins (With 10\% lead acetate solution) saponin (Foam Test), Proteins (Millon's Reagent test), steroids (Salkowski reaction) essential oils (Oil stain test), carbohydrates (Molisch's test) and glycosides (Legal's test). ${ }^{23-25}$

\section{Animals and Housing}

Wistar rats (170-230 g) of both sexes were maintained in the animal house of the Central Animal Facility, Jaypee University, Solan (H.P.) INDIA, under standard conditions like their housing temperature, relative humidity, light: dark cycle and air changes were maintained at
$22 \pm 3^{\circ} \mathrm{C}, 30$ to $70 \%, 12-12 \mathrm{~h}, 12-15$ air changes per hour, respectively. All the animals had access to standard rodent feed and RO water (ad libitum). All procedures were carried out after approval and under strict compliance with ethical principles, guidelines of the Institutional Animal Ethics Committee (3/GLG/2014/JUIT/IAEC), constituted as per CPCSEA (Committee for the Purpose of Control And Supervision of Experiments on Animals) (1716/PO/a/13/CPCSEA).

\section{Experimental design}

Animals were divided into six groups normal control (saline treatment), disease control, treatment control (Bacopa monnieri extract 100, 200, $300 \mathrm{mg} / \mathrm{kg}$ ) and standard control (fluoxetine (10 mg/kg i.p) comprising six animals each and housed individually. A modified liquid diet with or without ethanol was given to the rats ad libitum no other chow or water was supplied. Sucrose as a caloric substitute to ethanol was fed to the control group rats with an isocaloric diet and all other experiment groups animals were exposed to the ethanol treatment with modified liquid diet as described in previous studies. ${ }^{26-27}$ Modified liquid diet was prepared as per earlier studies which contain cow milk $925 \mathrm{ml}, 25-75 \mathrm{ml}$ ethanol (96.5\% ethyl alcohol), vitamin A 5000 IU and sucrose 17 g. ${ }^{26}$ At the beginning of the study, rats were given a modified liquid diet without ethanol for 7 days and then $2.4 \%$ ethanol was administered with a liquid diet for 3 days. Ethanol concentration was increased to $4.8 \%$ in the following 4 days and finally $7.2 \%$ for 21 days. After 21 days, ethanol was withdrawn from the diet by replacing with one without ethanol. Bacopa monnieri extract (100, 200 and $300 \mathrm{mg} / \mathrm{kg}$, oral), Fluoxetine (10 mg/kg i.p) and saline were injected into the rats $30 \mathrm{~min}$ before ethanol withdrawal testing. The animals were then examined at the $6^{\text {th }}$ and $24^{\text {th }} \mathrm{h}$ of the withdrawal period for the withdrawal signs like depressive behavior and locomotor hyperactivity using the tail suspension test, forced swim test and actophotometer models. Between observation periods, animals were returned to their home cages. After $24 \mathrm{~h}$ of the first dose, each group received another dose of its original drug. A parallel to ethanol-dependent groups, control group animals receiving liquid diet without ethanol were also evaluated for the withdrawal signs. All observations were carried out during the light period. Liquid diet was freshly prepared daily and presented at the same time $(09: 00 \mathrm{~h})$ of the day. Ethanol intake of the animals and their body weight was measured daily and expressed as $g$ per kg per day. On protocol completion animals were sacrificed by cervical dislocation and brain, liver, kidney were isolated and preserved in formalin for further histopathological studies. ${ }^{28-29}$

\section{Evaluation of depressive-like behavior induced by ethanol withdrawal Tail suspension test}

In tail suspension test rats were suspended on the edge of a table $58 \mathrm{~cm}$ above the floor by the adhesive tape placed approximately $2-3 \mathrm{~cm}$ from the tip of the tail. The duration of immobility was recorded for a period of $5 \mathrm{~min}$ and observed to the extent of immobility versus active movement. The animal was considered to be immobile when it does not show any movement of the body and remain hanging passively. ${ }^{30}$

\section{Forced Swim Test}

In forced swim test rats were individually forced to swim in a transparent vertical glass cylinder $\left(45 \mathrm{~cm}\right.$ high, $20 \mathrm{~cm}$ in diameter) filled with $27^{\circ} \mathrm{C}$ water to a depth of $20 \mathrm{~cm}$. The duration of immobility of the animal (in sec) was measured for 6 min. 'Immobility' was defined as floating and treading water just enough to keep the nose above water. The water was changed for each animal. ${ }^{31}$

\section{Evaluation of ethanol withdrawal locomotor hyperactivity}

For evaluation of spontaneous locomotor activity, rats were first individually placed in the actophotometer and the count of the movement of the animal cuts off a beam of light falling on the photocell is recorded 
digitally. After five minutes, the counter was stopped and the reading noted. The animal was then removed and the counter resets to zero. The same procedure was repeated for all animals. ${ }^{28}$

\section{Histopathological Studies}

The isolated organs were fixed in $10 \%$ neutral buffered formalin. The histological sections $(5 \mu \mathrm{m})$ of the tissues were stained with hematoxylin and eosin and examined under the microscope for any cellular damage or change. ${ }^{32}$

\section{Statistical Analysis}

Body weights of ethanol control rats as compared with normal control rats were analyzed by Student's t-test. Two-way ANOVA (Analysis of variance) followed by Bonferroni's multiple comparison test was used in the evaluation of the effects of Bacopa monnieri in the tail suspension test, forced swim test and locomotor activities. The level of significance was set at $p<0.001$ levels.

\section{RESULTS}

\section{Phytochemical screening of the plant extract}

The phytochemical screening of the Bacopa monnieri extract revealed the presence of flavonoids, alkaloids, tannins, saponin, proteins, steroids, essential oils, carbohydrates and glycosides.

\section{Ethanol consumption and body weight changes of the rats}

Daily ethanol consumption in ethanol-treated rats ranged from $12.18 \pm$ 0.91 to $15.39 \pm 0.81 \mathrm{~g} / \mathrm{kg}$. There was no significant difference between the groups was observed. Body weight gain over the initial body weight of the animals (3.96\% ethanol-fed and $15.20 \%$ in the control group) was observed at the end of the study. Body weight changes in the control and ethanol-fed rats are presented in Table 1.

\section{Tail suspension test}

Ethanol-fed rats showed a significantly increased immobility time in the tail suspension test on the $6^{\text {th }}$ and $24^{\text {th }} \mathrm{h}$ of the withdrawal period as compared with the normal saline group. Treatment with Bacopa monnieri extract $(100,200$ and $300 \mathrm{mg} / \mathrm{kg}$, oral $)$ and fluoxetine $(10 \mathrm{mg} / \mathrm{kg}$ i.p) at the $6^{\text {th }}$ and $24^{\text {th }} \mathrm{h}$ of ethanol withdrawal produced the significant decrease in the immobility time as compared to the disease control rats (Figure 1).

\section{Forced swim test}

Ethanol-fed rats showed a significantly increased immobility time in the forced swim test on the $6^{\text {th }}$ and $24^{\text {th }} \mathrm{h}$ of the withdrawal period as compared with the normal saline group. Treatment with Bacopa monnieri extract $(100,200$ and $300 \mathrm{mg} / \mathrm{kg}$, oral $)$ and fluoxetine $(10 \mathrm{mg} / \mathrm{kg}$ i.p) at the $6^{\text {th }}$ and $24^{\text {th }} \mathrm{h}$ of ethanol withdrawal produced the significant decrease in the immobility time as compared to the disease control rats (Figure 2).

\section{Locomotor activity}

Ethanol-fed rats showed a significant increased locomotor activity on the $6^{\text {th }}$ and $24^{\text {th }} \mathrm{h}$ of the withdrawal period as compared with the normal saline group. Bacopa monnieri extract $(100,200$ and $300 \mathrm{mg} / \mathrm{kg})$ and fluoxetine $(10 \mathrm{mg} / \mathrm{kg}$ i.p) treatment produced significant inhibitory effects on locomotor hyperactivity at the $6^{\text {th }}$ and $24^{\text {th }}$ hour of ethanol withdrawal (Figure 3).

\section{Histopathology}

Histopathology of the brain showed normal glial cells, the liver showed normal hepatocytes and kidney revealed normal nephrons without any interstitial bleeding and glomerular congestion. Alcohol consumption and withdrawal did not induce any remarkable and treatment-related gross pathological and microscopic changes in the alcohol-fed and drugtreated rats when compared to the normal control (Figure 4).

\section{DISCUSSION}

The present study showed that the Bacopa monnieri treatment reverses the depressive-like behavior induced by alcohol withdrawal in rats. Ethanol administration in a liquid diet is the most appropriate model for exploring ethanol withdrawal syndrome in rats. ${ }^{26,33}$ Abstinence from chronic intake of ethanol is known to produce withdrawal signs and depressive-like behavior is most common among them. ${ }^{34}$ In present study approximately $15.9 \%$ increase in body weights of control rats was observed and there was a $5.2 \%$ increase in the body weights of the ethanol feeding rats. This observation agrees with previous reports on the effects of alcohol on digestion, as alcohol damages the cells lining the stomach and intestines; impairs nutrient absorption by disabling transport of some

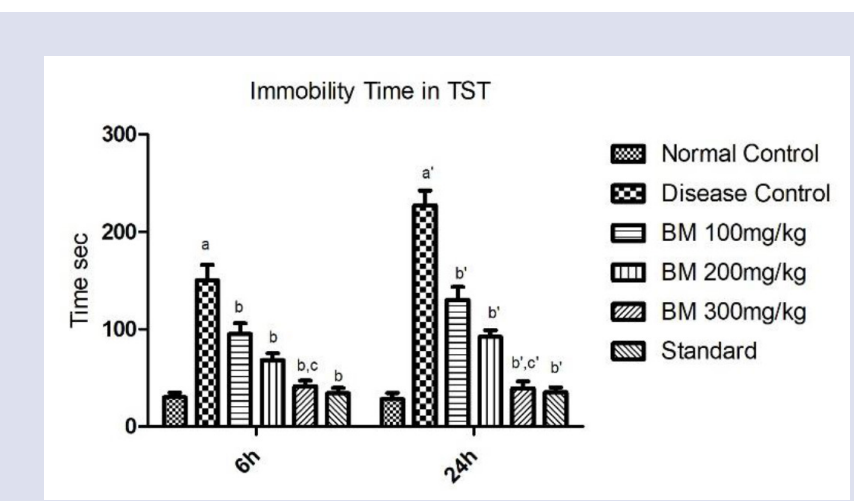

Figure 1: Effect of drug treatment on alcohol withdrawal depressivelike behavior when tested on tail suspension test Figure1 Results: mean \pm SD analyzed by two-way ANOVA followed by Bonferroni's multiple comparison test; a $p<0.001$ vs NC, b $p<0.001$ vs $D C, c p<0.001$ vs fluoxetine after $6^{\text {th }}$ h. $a^{\prime} p<0.001$ vs NC, $b^{\prime} p<0.001$ vs $D C, c^{\prime} p<0.001$ vs fluoxetine after $24^{\text {th }} \mathrm{h}$.

$\mathrm{BM}=$ Bacopa monnieri, $\mathrm{NC}=$ Normal control, $\mathrm{DC}=$ Disease control.

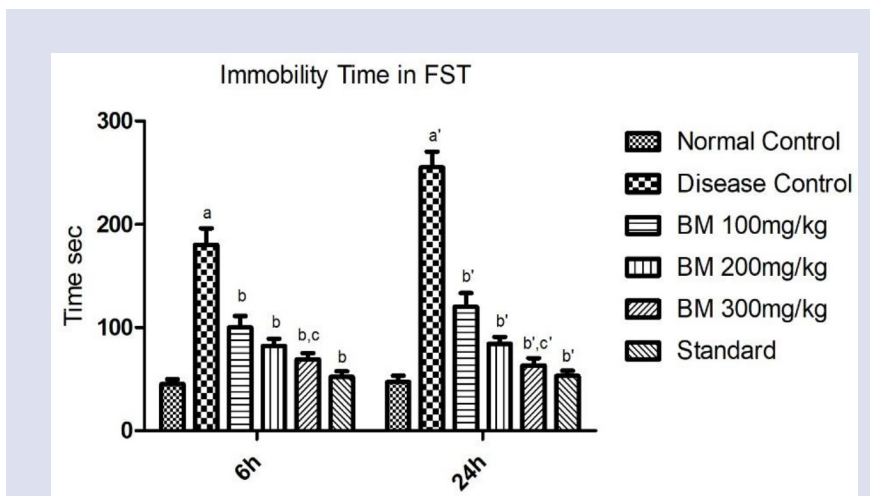

Figure 2: Effect of drug treatment on alcohol withdrawal depressive-like behavior when tested on forced swim test Figure 2 Results: mean \pm SD analyzed by two-way ANOVA followed by Bonferroni's multiple comparison test; a $p<0.001$ vs NC, b $p<0.001$ vs $D C, c p<0.001$ vs fluoxetine after $6^{\text {th }}$ h. $\mathrm{a}^{\prime} p<0.001$ vs NC, $\mathrm{b}^{\prime} p<0.001$ vs $D C, c^{\prime} p<0.001$ vs fluoxetine after $24^{\text {th }} \mathrm{h}$.

$\mathrm{BM}=$ Bacopa monnieri, $\mathrm{NC}=$ Normal control, $\mathrm{DC}=$ Disease control. 


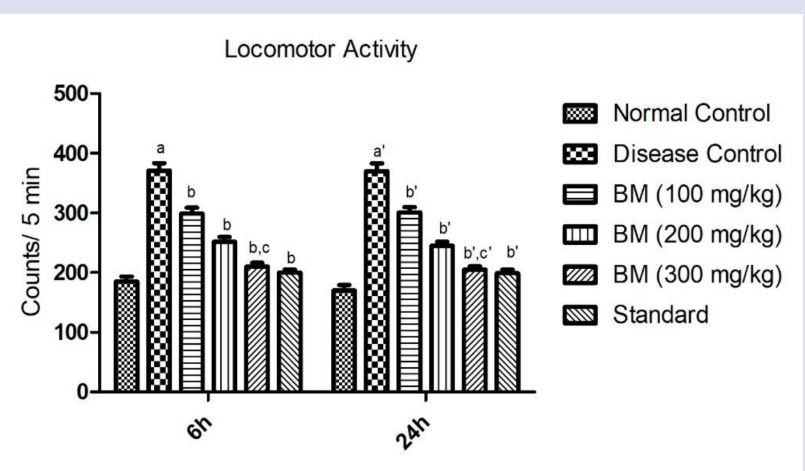

$\mathrm{BM}=$ Bacopa monnieri, $\mathrm{NC}=$ Normal control, $\mathrm{DC}=$ Disease control.

Figure 3: Effect of drug treatment on locomotor hyperactivity when tested on actophotometer Results: mean \pm SD analyzed by two-way ANOVA followed by Bonferroni's multiple comparison test; a $p<0.001$ vs NC, b $p<0.001$ vs DC, $c p<0.001$ vs fluoxetine after $6^{\text {th }} h . a^{\prime} p<0.001$ vs $N C, b^{\prime} p<0.001$ vs $D C, c^{\prime} p<0.001$ vs fluoxetine after $24^{\text {th }} \mathrm{h}$.

$\mathrm{BM}=$ Bacopa monnieri, $\mathrm{NC}=$ Normal control, $\mathrm{DC}=$ Disease control.

nutrients into the blood. ${ }^{35}$ During the study, rats displayed increased immobility in the forced swim test and tail suspension test after $6^{\text {th }}$ and $24^{\text {th }} \mathrm{h}$ of withdrawal from ethanol. These results are similar to earlier findings describing that ethanol withdrawal induces depressive-like effects in rats. ${ }^{36-37}$ Previous findings suggest that depressive-like behavior induced by alcohol withdrawal is associated with a reduction in hippocampal brain-derived neurotrophic factor (BDNF), which is responsible for neuronal development, plasticity and survival. ${ }^{38}$ Our study revealed that Bacopa monnieri extract treatment at doses 100, 200 and $300 \mathrm{mg} / \mathrm{kg}$ in ethanol withdrawal rats decreased the immobility time in forced swim test and tail suspension test. Bacopa monnieri at doses 100, 200 and $300 \mathrm{mg} / \mathrm{kg}$ produced a significant antidepressant effect in ethanolwithdrawn rats. The antidepressant effects of Bacopa monnieri in animal models of depression have been well documented in the literature. Earlier findings also suggested that Bacopa monnieri inhibits the reuptake of several synaptosomal neurotransmitters such as serotonin, dopamine, noradrenaline and modulates neuronal excitability via glutamatergic and GABAergic mechanisms. ${ }^{22}$ The studies have postulated the role of GABA and serotonin in the mechanism of action of Bacopa monnieri attributed for its antidepressant properties. Previous findings reported the antidepressant effects of Bacopa monnieri in normal rats while our study is reporting the antidepressant properties of Bacopa monnieri using an ethanol withdrawal model for the first time. Fluoxetine $(10 \mathrm{mg} / \mathrm{kg}$ i.p) a selective serotonin reuptake inhibitor (SSRI) and a potent antidepressant drug were used as a standard. Locomotor hyperactivity is another easily assessable behavioral sign of ethanol withdrawal. ${ }^{28}$ Ethanol-dependent rats showed a significant locomotor hyperactivity at the $6^{\text {th }}$ and $24^{\text {th }} \mathrm{h}$ of the alcohol withdrawal when compared to the ethanol nondependent rats. Locomotor hyperactivity of the ethanol withdrawal rats was similar to the previous studies. ${ }^{27-28}$ Bacopa monnieri extract at 100, 200 and $300 \mathrm{mg} / \mathrm{kg}$ significantly normalized the locomotor hyperactivity when tested in the actophotometer. Brain, liver and kidney are the major organs affected by the chronic ethanol intake, however, histopathological examination confirmed that alcohol dependence and withdrawal did not induce any pathological and microscopic alterations in the experimental animals. The phytochemical screening of the hydroalcoholic extract of Bacopa monnieri showed the presence of flavonoids, alkaloids, tannins, saponin, proteins, steroids, essential oils, carbohydrates and glycosides which may

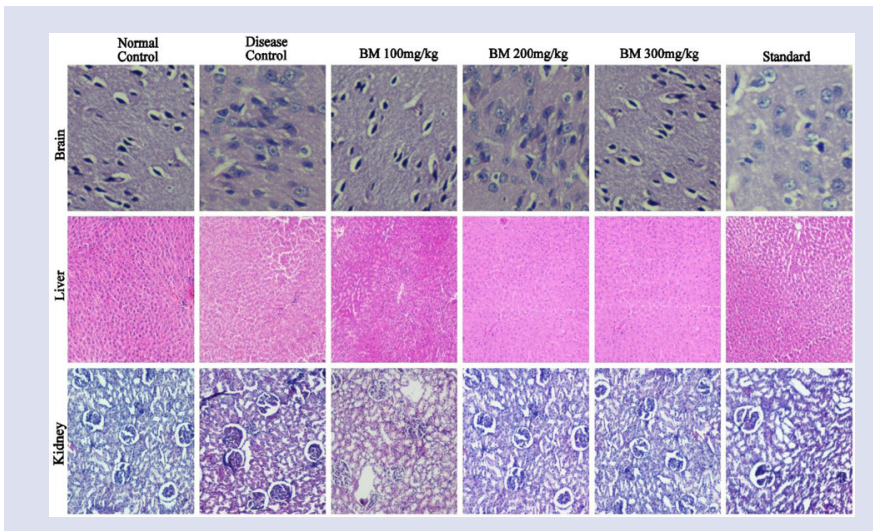

Figure 4: Histology of brain, liver and kidney ( $\mathrm{H}$ and $\mathrm{E} \times 100)$.

Table 1: Body weight changes of the rats fed with the liquid diet with or without ethanol.

\begin{tabular}{cccc}
\hline \multicolumn{4}{c}{ Body Weight $(\mathrm{g})$} \\
\hline Groups & $\begin{array}{c}\text { Beginning of the } \\
\text { study }\end{array}$ & $\begin{array}{c}\text { End of the } \\
\text { study }\end{array}$ & $\begin{array}{c}\text { Body weight } \\
\text { change (\%) }\end{array}$ \\
Control & $218.91 \pm 5.32$ & $252.19 \pm 5.28$ & $15.20 \%$ \\
Ethanol fed & $225.41 \pm 4.39$ & $234.34 \pm 5.91$ & $3.96 \%$ \\
\hline
\end{tabular}

play a protective role in reverting the ethanol withdrawal depressive-like behavior possibly by glutamatergic and GABAergic mechanisms.

\section{CONCLUSION}

In conclusion, the present study showed that the Bacopa monnieri extract reverts the depressive-like behavior and locomotor hyperactivity induced by ethanol withdrawal in alcohol-dependent rats. Therefore, it may have therapeutic potential in the treatment of ethanol-type dependence by suppressing ethanol withdrawal signs and symptoms.

\section{ACKNOWLEDGEMENT}

The authors thank Science and Engineering Research Board (SERB), Department of Science and Technology, Government of India for financial support for this work (SR/FT/LS-07/2012).

\section{CONFLICT OF INTEREST}

The authors declare no conflict of interest.

\section{ABBREVIATIONS}

NMDA: N-Methyl-D-aspartic acid; $\mathbf{G A B A}_{\mathrm{A}}: \gamma$-aminobutyric acid; ANOVA: Analysis of variance; DTs: Delirium tremens; SSRI: Selective Serotonin Reuptake Inhibitor.

\section{REFERENCES}

1. Fiellin DA, O'Connor PG, Holmboe ES, Horwitz RI. Risk for delirium tremens in patients with alcohol withdrawal syndrome. Subst Abuse. 2002;23(2):83-94.

2. Hall W, Zador DZ. The alcohol withdrawal syndrome. Lancet. 1997; 349(9069):1897-900.

3. Holbrook AM, Crowther R, Lotter A, Cheng C, King D. Diagnosis and management of acute alcohol withdrawal. Canadian Medical Association Journal. 1999;160(5):675-80.

4. Lerner WD, Fallon HJ. The alcohol withdrawal syndrome. N Engl J Med. 1985;313(15):951-2

5. Bonassoli VT, Milani H, Oliveira RMD. Ethanol withdrawal activates nitric oxideproducing neurons in anxiety-related brain areas. Alcohol. 2011;45(7):641-52.

6. Knapp DJ, Overstreet DH, Angel RA, Navarro M, Breese GR. The amygdala regulates the antianxiety sensitization effect of flumazenil during repeated 
chronic ethanol or repeated stress. Alcohol Clin Exp Res. 2007;31(11):1872-82.

7. Dodd PR, Beckman AM, Davidson MS, Wilce PA. Glutamate mediated transmission, alcohol and alcoholism. Neurochemistry Internatioinal. 2000;37(5-6):509-33.

8. Ross HE. Benzodiazepine use and anxiolytic abuse and dependence in treated alcoholics. Addiction. 1993;88(2):209-18.

9. Heilig M, Egli M. Pharmacological treatment of alcohol dependence: target symptoms and target mechanisms. Pharmacol Ther. 2006;111(3):855-76.

10. Sharma A, Sharma L, Goyal R. A Review on Himalayan Pine Species: Ethnopharmacological, Phytochemical and Pharmacological Aspects. Pharmacognosy Journal. 2018;10(4):611-9.

11. Sharma L, Sharma A, Gupta GL. Standardization of a Polyherbal Preparation (POL-6) for treatment of Oxidative, Inflammatory and Immune Disorders. Int J Pharm Pharm Sci. 2016;8(4): 129-34.

12. Barrett SC, Strother JL. Taxonomy and natural history of Bacopa (Scrophulariaceae) in California. Syst Bot. 1978;3(4):408-19.

13. Singh HK, Dhawan BN. Neuropsychopharmacological effects of the Ayurvedic nootropic Bacopa monniera Linn. (Brahmi). Ind J Pharmacol. 1997;29(5):359-65.

14. Russo A, Borrelli F. Bacopa monniera, a reputed nootropic plant: an overview. Phytomedicine. 2005;12(4):305-17.

15. Kishore K, Singh M. Effect of bacosides, alcoholic extract of Bacopa monniera Linn. (brahmi), on experimental amnesia in mice. Ind J Exp Biol. 2005;43(7):640-5.

16. Anbarasi K, Vani G, Balakrishna K, Devi CS. Creatine kinase isoenzyme patterns upon chronic exposure to cigarette smoke: protective effect of Bacoside A. Vascul Pharmacol. 2005;42(2):57-61.

17. Singh HK, Rastogi RP, Srimal RC, Dhawan BN. Effect of bacosides A and B on avoidance responses in rats. Phytother Res. 1988;2(2):70-5.

18. Joshua AJ, Damodaran A, Deshmukh NS, Goudar KS, Amit A. Safety evaluation of a standardized phytochemical composition extracted from Bacopa monnieri in Sprague - Dawley rats. Food and Chemical Toxicology. 2007;45(10):1928-37.

19. Bhatia G, Dhuna V, Dhuna K, Kaur M, Singh J. Bacopa monnieri extracts prevent hydrogen peroxide-induced oxidative damage in a cellular model of neuroblastoma IMR32 cells. Chin J Nat Med. 2017;15(11):834-46.

20. Bhattacharya SK, Bhattacharya A, Kumar A, Ghosal S. Antioxidant activity of Bacopa monniera in rat frontal cortex, striatum and hippocampus. Phytother Res. 2000;14(3):174-9.

21. Bhattacharya SK, Ghosal S. Anxiolytic activity of a standardized extract of Bacopa monniera - an experimental study. Phytomedicine. 1998;5(2):77-82.

22. Sairam K, Dorababu M, Goel RK, Bhattacharya SK. Antidepressant activity of standardized extract of Bacopa monniera in experimental models of depression in rats. Phytomedicine. 2002;9(3):207-11.

23. Sharma A, Goyal R, Sharma L. Potential biological efficacy of Pinus plant species against oxidative, inflammatory and microbial disorders. BMC Complement Altern Med. 2015;16(1):35
24. Sharma L, Sharma A. In vitro antioxidant, anti-inflammatory and antimicrobial activity of hydro-alcoholic extract of roots of Withania somnifera. J Chem Pharm Res. 2014;6(7):178-82

25. Tewari I, Sharma L, Gupta GL. Synergistic antioxidant activity of three medicinal plants Hypericum perforatum, Bacopa monnieri and Camellia sinensis. Indo Am J Pharm Res. 2014:4(5):2563-8.

26. Uzbay IT, Kayaalp SO. A modified liquid diet of chronic ethanol administration: validation by ethanol withdrawal syndrome in rats. Pharmacol Res. 1995; 31(1):37-42

27. Sharma L, Sharma A, Gupta GL, Bisht GS. Protective effect of Ocimum sanctum Linn. leaf extract on ethanol withdrawal syndrome in Wistar rats. Asian Pac J Trop Med. 2018; $11(8): 467-72$

28. Unsalan N, Saglam E, Kayir H, Uzbay T. Effects of olanzapine on ethanol withdrawal syndrome in rats. Eur J Pharmacol. 2008;579(1-3):208-14.

29. Bruzda EG, Grabska MM, Witkowska E, Izdebski J, Kotlinska JH. Enkephalin analog, cyclo[ $\left[N^{\varepsilon}, N^{\beta}\right.$-carbonyl-D-Lys $\left.{ }^{2}, D^{2} p^{5}\right]$ enkephalinamide (cUENK6), inhibits the ethanol withdrawal-induced anxiety-like behavior in rats. Alcohol. 2015;49(3):229-36.

30. Steru $L$, Chermat $R$, Thierry B, Simon P. Tail suspension test: A new method for screening antidepressants in mice. Psychopharmacology. 1985;85(3):367-70.

31. Slattery DA, Cryan JF. Using the rat forced swim test to assess antidepressantlike activity in rodents. Nat Protoc. 2012;7(6):1009-14.

32. Tchamadeu MC, Dzeufiet PD, Nana P, Kouambou NCC, Ngueguim TF, Allard J, et al. Acute and sub-chronic oral toxicity studies of an aqueous stem bark extract of Pterocarpussoyauxii Taub (Papilionaceae) in rodents. J Ethnopharmacol. 2011;133(2):329-35.

33. Saglam E, Kayir H, Celik T, Uzbay T. Effects of escitalopram on ethanol withdrawal syndrome in rats. Prog Neuropsychopharmacol Biol Psychiatry. 2006;30(6):1027-32

34. Greenfield SF, Weiss RD, Muenz LR, Vagge LM, Kelly JF, Bello LR, et al. The effect of depression on return to drinking: a prospective study. Arch Gen Psychiatry. 1998;55(3):259-65.

35. Feinman L, Lieber CS. Nutrition and diet in alcoholism. In: Shills, ME, Oslon JA Shike, M. Ross AC. eds. Modern Nutrition in Health and disease. $9^{\text {th }}$ ed. Baltimore: Williams and Wilkins. 1998;1523-42

36. Stevenson JR, Schroeder JP, Nixon K, Besheer J, Crews FT, Hodge CW. Abstinence following alcohol drinking produces depression-like behavior and reduced hippocampal neurogenesis in mice. Neuropsychopharmacology. 2009;34(5):1209-22.

37. Kotwal S, Upaganlawar AB, Mahajan M, Upasani C. Protective Effects of Ferulic Acid in Alcohol Withdrawal Induced Anxiety and Depression in Mice. Malays $J$ Med Biol Res. 2015;2(3):231-6.

38. Hauser SR, Getachew B, Taylor RE, Tizabi Y. Alcohol induced depressive-like behavior is associated with a reduction in hippocampal BDNF. Pharmacol Biochem Behav. 2011;100(2):253-8.

\section{GRAPHICAL ABSTRACT}

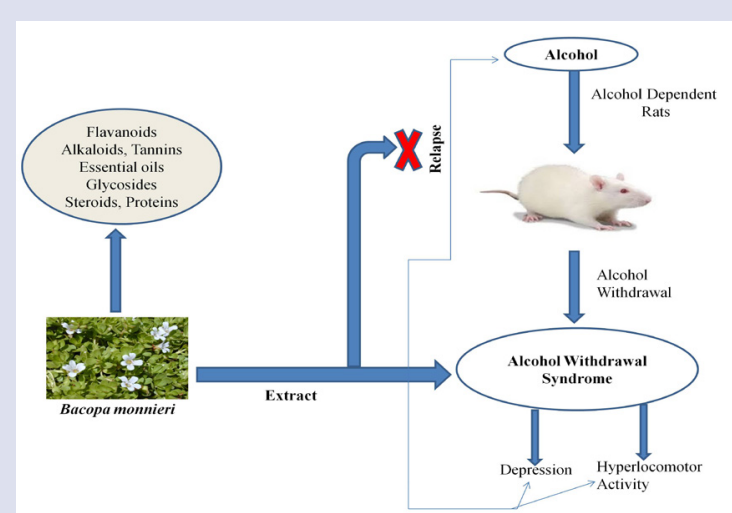

\section{SUMMARY}

- Alcoholism is a chronic, relapsing disorder which is characterized by compulsive alcohol drinking. Alcohol withdrawal syndrome lead to relapse to alcohol use and depression is the most common symptom of withdrawal.

- Bacopa monnieri is a traditional memory enhancer and is used for the treatment of anxiety and in improving intellect and memory.

- The results from the present study showed that the Bacopa monnieri extract may have therapeutic potential in the treatment of ethanol-type dependence as it reverts the depressive-like behavior and locomotor hyperactivity induced by ethanol withdrawal in alcohol-dependent rats.

\section{ABOUT AUTHORS}

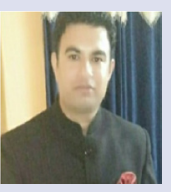

Lalit Sharma has received his M.Pharm degree in Pharmacology in year 2013 and now he is Pursuing PhD from Jaypee University Information Technology, Waknaghat, Solan. He is working on the drug addiction problems in humans and his area of interest is Drug Addiction and Neuropharmacology.

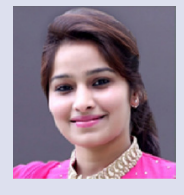

Aditi Sharma has received her M.Pharm degree in Pharmacology in year 2014 and now Pursuing PhD from Shoolini University, Solan. She is also working as an Assistant Professor (Pharmacology) in School of Pharmaceutical Sciences, Shoolini University. Her area of interest is drug addition and osteoporosis. 


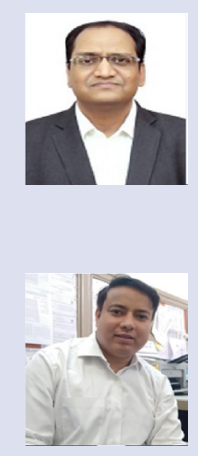

Dr. Girdhari Lal Gupta has received his M. Pharm degree in Pharmacology and PhD in Pharmaceutical Sciences in year 2005 and 2009, respectively. He is currently working as an Associate Professor, Department of Pharmacology at SPP School of Pharmacy and Technology Management, SVKM's NMIMS University, Mumbai, India. He has published several scientific papers in peer-reviewed journals. He has also received Government funded research projects from Science Engineering and Research Board, Indian Council of Medical Research. He has also been nominated as CPCSEA Member by Animal Welfare Division, Ministry of Environment, Forests and Climate Change, Government of India.

Dr. Gopal Singh Bisht is a trained and experienced organic chemist with 6 years of post Ph.D. experience in research. He is working as an Associate professor in the department of BT and $\mathrm{BI}$ at Jaypee University of Information Technology, Solan. He has also worked as a Research Scientist at Ranbaxy research Laboratory. Dr. Bisht has carried out his PhD work at Institute of Genomics and Integrative Biology (CSIR), where he worked on synthesis and biological evaluation of antimicrobial peptides and got his $\mathrm{PhD}$ in Chemistry from University of Delhi, New Delhi, India, He has published his research work in peer reviewed journals. He is interested in design and synthesis of Peptides, Peptidomimetics and Heterocyclic compounds as antimicrobial and anticancer agents, natural product chemistry and drug addiction.

Cite this article: Sharma L, Sharma A, Gupta GL, Bisht GS. Pharmacological Evaluation of Bacopa monnieri Extract against Depressive like Behavior Induced by Ethanol Withdrawal in Rats. Pharmacog J. 2018;10(6)Suppl:s48-s53. 